\title{
Randomised controlled trial of early discharge for inguinal hernia and varicose veins
}

\author{
M. W. ADleR, J. J. WALLER, A. CREESE, AND \\ S. C. THORNE \\ From the Department of Community Medicine, St. Thomas's Hospital Medical School, London
}

SUMMARY A randomised controlled trial has been conducted into the effects of discharging patients from hospital either $\mathbf{4 8}$ hours or six to seven days after operations for inguinal hernia and varicose veins. There was no statistically significant difference in major postoperative complications between the two lengths of stay for either of the two conditions. Similarly there was no difference between the two groups of hernia patients in relation to eventual recurrences. There was no significant difference in length of convalescence between long-stay and short-stay patients in full-time occupations. The savings to the statutory services of discharging patients early were estimated at $£ 25.72$ per patient. Patients appeared to approve of the type of care they experienced, regardless of length of stay. However, the families of short-stay patients were significantly less enthusiastic in their attitudes towards the policy of early discharge than the families of long-stay patients.

\section{Introduction}

Concern about the length of time patients spend either in bed or in hospital is not new (Ries, 1899) although it is particularly fashionable in the current movement towards community care. Reports published in the last 30 years have studied the feasibility and techniques of outpatient or short-stay surgery with control populations (Blodgett and Beattie, 1946, 1947; Morris et al., 1968; Echeverri et al., 1972; Gerson and Berry, 1976; Russell et al., 1977) and without control populations (Farquharson, 1955; Stephens and Dudley, 1961 ; Iles, 1965; Lord, 1969; Ruckley et al., 1973). In addition there have been a number of reports drawing attention to the problems posed by long waiting lists and differing policies of management (Heasman, 1964; Chant et al., 1972).

Most of these studies have been limited to the surgical and administrative problems and it is only more recently that the effects of outpatient surgery and early discharge on both the providers and the consumers of the service have been investigated (Dean and Wilkinson, 1969; Hockey, 1970; Ruckley et al., 1971; Doran et al., 1972; Drury et al., 1973). Nearly all the studies of the wider implications of early discharge were simply descriptions of a system of care, and no attempt was made to carry out comparisons with a control group. There are a few exceptions (Echeverri et al., 1972; Gerson and Berry,
1976; Russell et al., 1977) but those studies allo started after the present one.

At the time when our study was planned, there had been no randomised controlled trials of early discharge in which the effects on the patient and his family, the community services, and the hospital had been measured. This study was therefore planned to provide information to fill this important gap. ' . . . Measurements of mortality, morbidity, disability, discontent and discomfort, together with their economic, social and psychological effects, are needed for decisions to be taken on the efficient use of resources'. (King Edward's Hospital Fund for London, 1973).

\section{Methods}

Patients undergoing surgery for inguinal hernia or varicose veins were randomly allocated into two lengths of postoperative stay, 48 hours and six to seven days. Several aspects of hospital and community care were investigated, and differences were studied from the point of view of the patients, their families, and the providers of care. In addition, various aspects of hospital and community care were costed.

STUDY AREA AND POPULATION

The study was carried out in Farnham and Frimley, approximately 35 miles south of London. A 
geographical area had previously been defined, corresponding to the catchment area of the new 'best buy' hospital which was being built at Frimley (Clarke and Bennett, 1971).

The study population in this area comprised 220000 people. The study ran from January 1971 to March 1973 and covered five cottage hospitals and the acute general hospital.

\section{GENERAL PRACTITIONERS AND}

DOMICILIARY STAFF

Primary medical care in the study area was being provided by 119 practitioners, of whom 116 agreed to take part. The district nurses and home helps who took part were not especially employed or recruited for the study, but included staff already in the area who were asked to visit study patients in the course of their work. Home helps were offered free of charge for the first five days after leaving hospital to patients whose length of stay was 48 hours. Fifty-two nurses and 21 home helps took part in the study.

\section{SURGEONS AND OPERATIVE PROCEDURES}

The surgery for study patients was undertaken by the three consultants normally working in the six hospitals and by their shared registrar. No standard procedure was stipulated for preoperative preparation, anaesthetic, or type of operation. The details of the different types of operations used are reported elsewhere (Adler, 1977a).

\section{CLINICAL OUTCOME}

The main variables in the clinical part of the study were the number and type of complications, recurrence rate, and the length of the patients' convalescence. Information about complications was collected up to the time when patients were seen at outpatient follow-up, approximately six weeks after discharge. Data on complications were collected by consulting surgeons or house surgeons, hospital and district nurses, and general practitioners. One hundred and sixteen of the 117 short-stay patients were visited at home by the district nurses compared with only two of the 107 long-stay patients. As a result, more data were collected from the former group and the two groups were therefore not comparable. To achieve comparability, it was decided to look at complications in the two groups of patients using all the reporting sources mentioned, but to take a cut-off point seven days after the operation, the period that long-stay patients remained in hospital.

Recurrences were measured only for the patients undergoing inguinal hernia surgery. In the varicose vein patients, the extent of underlying damage of the venous system is of crucial importance in the risk of recurrences, and because it was impossible to measure such damage, no attempt was made to study recurrences in these patients.

The date of return to work or normal activity (for housewives) could be collected from one or more sources (Adler et al., 1974). These were the surgeon at outpatient follow-up, the general practitioner responsible for certifying days off work, the patient in the course of an interview two weeks after the operation, and routine sickness absence data.

\section{Costs}

The concept of social cost was used for making comparisons. This includes more than the financial costs to the producer (in this case the National Health Service). Social cost can be defined as the real sacrifices made by all concerned as a result of a particular policy. In the present study, this includes all the costs of all the statutory service providers, the costs to the patient and his or her family, and the costs borne by the community as a result of valuable working time lost because of illness and convalescence.

\section{STATUTORY SERVICES}

Hospital costs comprise two separate elementsshared and individual costs. Shared costs are those which can be divided equally among patients on the basis of length of stay, regardless of diagnosis and eventual treatment. The methodology used to construct daily costs was based on a comparative survey of hospital costing undertaken elsewhere (Mason et al., 1973). This was considered more suitable than the use of average cost figures. The shared component of hospital stay was calculated for each of the study hospitals by computing a daily rate from the summary of hospital costs (South-west Metropolitan Regional Hospital Board, 1972) for 1971-72, the financial year in which most of the patients in the study had their operations.

Individual costs depend on the particular type of case and could therefore be expected to differ between patients with minor and major conditions, and between those with the same condition but different lengths of stay. Once again, use was made of hospital cost returns but costs were also obtained from a work study carried out among a number of short-stay patients.

The costs of general practitioners, district nurses, and home helps were calculated using average gross remuneration on existing salary scales. Administrative and transport costs were included where appropriate. 
PATIENTS' AND HOUSEHOLD COSTS

The economic consequences of illness and treatment are not confined to the health service. The patient's household will also be financially affected in a variety of ways (Abel-Smith, 1976). Details of these costs were obtained by personal interviews with patients and their families.

\section{COMMUNITY COSTS}

Whether a patient works in the home or outside it, any time off means that the effects of that work are lost, be it in terms of cars produced or the provision of domestic services. This is a cost or resource loss to the community through its effect on the national product. Because sick pay arrangements are not standardised, the best measure of the economic loss to the community is the total of productive time lost-that is, the number of days off work, rather than the total of an individual's actual losses of income. Theoretically, wages plus employer's contributions measure the value of an employee's contribution to output. Wage rates, increased by $15 \%$ to incorporate contributions, and multiplied by the days lost, have been used to compute the morbidity component of the total social cost (Rice, 1966). The convalescent time of women was valued at women's wage rates, regardless of whether or not they were formally employed. This was done to avoid under-representing the economic loss of a housewife's services.

When calculating the length of convalescence and time off work, the length of time before return to work was taken for those with jobs. For housewives without jobs, we took the time between the operation and resumption of normal household activities.

\section{ATTITUDES}

All patients' attitudes were measured using Likerttype scales (Likert, 1932). The questionnaire consisted of statements with which patients were asked to agree or disagree on a five-point scale, from 'strongly agree' to 'strongly disagree'. Each patient also completed a semantic differential form about his or her self-image (Osgood et al., 1951).

Fourteen days after the patient's operation, the household member responsible for looking after the patient was asked what he or she thought about the practice of early discharge, particularly in relation to the burden this placed on the family and the worry it caused.

General practitioners were asked to complete two questionnaires at the end of the study in an attempt to assess what they thought about early discharge. Similar information was obtained from each district nurse by a structured questionnaire given in an interview as soon as possible after her last visit to a short-stay patient.

\section{ADDITIONAL ASSISTANCE, HOUSEHOLD DISRUPTION, AND EFFECTS ON OTHER PATIENTS}

Information about additional help needed and disruption caused in the household was collected in an interview at home two weeks after the patient's operation. Another possible consequence of early discharge is that other patients suffer because of the loss of domiciliary services necessitated by redeployment of these services. Attempts were made to calculate the effects of this.

\section{Results}

NUMBER OF PATIENTS STUDIED

Patients with either an inguinal hernia or varicose veins came into the study if they were aged 18 to 64 years inclusive. Patients with recurrent hernias were excluded. Two hundred and twenty-four patients took part. Table 1 shows the number of patients by length of stay, sex, and condition.

Table 1 Number of patients by length of stay, sex, and condition

\begin{tabular}{lllllll}
\hline & \multicolumn{2}{l}{ Short-stay } & \multicolumn{2}{l}{ Long-stay } & \\
\cline { 2 - 4 } Condition & Men & Women & & Men & Women & All patients \\
\hline Inguinal hernia & 54 & 2 & 46 & 3 & 105 \\
Varicose veins & 14 & 47 & 10 & 48 & 119 \\
Total & 68 & 49 & 56 & 51 & 224 \\
\hline
\end{tabular}

\section{COMPLICATIONS}

Table 2 shows the complications for patients with inguinal hernia and varicose veins recorded up to seven days after their operations. Although five of the 105 hernia operations were on women, all the complications occurred in men. The difference in complications between the two groups of hernia patients was not statistically significant. Of the 119 varicose vein operations, 95 were performed on women who experienced six of the total of eight complications. There were four major complications among the short-stay patients and none in the longstay group. This difference was not significant at a conventional level of $(P=0.065)$. If the minor complications are included, the difference between the two groups becomes statistically significant $(P=0.003$, Fisher's exact test) (Fisher, 1970). Even though it was agreed that the four vein complications should be classified as minor, the surgeons felt that these were of little importance. It was considered that persistent 'oozing' of the 
wound with no infection was due to lymph, and was normal; that the two 'plaster reactions' had nothing to do with length of stay; and that an upper respiratory tract infection more than $\mathbf{4 8}$ hours after an operation was unlikely to be related to it. The study surgeons were happy to accept that since major complications were so infrequent, early discharge for patients with both varicose veins and inguinal hernias was in no way contraindicated on clinical grounds.

Table 2 Complications recorded up to seven days after operation

\begin{tabular}{|c|c|c|c|}
\hline$\frac{\text { Inguinal hernia patients }}{\text { Type of complication }}$ & $\begin{array}{l}\text { Long-stay } \\
(n=49)\end{array}$ & $\begin{array}{c}\text { Short-stay } \\
(n=56)\end{array}$ & $\begin{array}{l}\text { Total } \\
(n=105)\end{array}$ \\
\hline $\begin{array}{l}\text { Wound infection } \\
\text { Chest infection } \\
\text { Haematoma } \\
\text { Stitch abscess } \\
\text { Scoline apnoea } \\
\text { Oedema of scrotum/penis }\end{array}$ & $\frac{2}{2 *}$ & $\begin{array}{l}2 \\
2^{*} \\
1 \\
1^{*} \\
\frac{1}{1}\end{array}$ & $\begin{array}{l}4 \\
4 \\
1 \\
1 \\
1 \\
1\end{array}$ \\
\hline Total & 5 & 7 & 12 \\
\hline
\end{tabular}

*Noted in hospital in first $\mathbf{4 8}$ hours

$x_{1}^{2}=0.095,0.7<P<0.8$

\begin{tabular}{|c|c|c|c|}
\hline$\frac{\text { Varicose vein patients }}{\text { Type of complication }}$ & $\begin{array}{l}\text { Long-stay } \\
(n=58)\end{array}$ & $\begin{array}{l}\text { Short-stay } \\
(n=61)\end{array}$ & $\begin{array}{l}\text { Total } \\
(n=119)\end{array}$ \\
\hline $\begin{array}{l}\text { Major } \\
\text { Wound infection } \\
\text { Haematoma } \\
\text { Thrombophlebitis }\end{array}$ & $\bar{z}$ & $\begin{array}{l}2 \\
1 * \\
1\end{array}$ & $\begin{array}{l}2 \\
1 \\
1\end{array}$ \\
\hline $\begin{array}{l}\text { Minor } \\
\text { Rash-'Plaster reaction' } \\
\text { Persistent 'Oozing } \\
\text { wound', no infection }\end{array}$ & - & $\begin{array}{l}2 \\
1\end{array}$ & $\begin{array}{l}2 \\
1\end{array}$ \\
\hline $\begin{array}{l}\text { Upper respiratory tract } \\
\text { infection }\end{array}$ & - & 1 & 1 \\
\hline Total & 0 & 8 & 8 \\
\hline
\end{tabular}

*Noted in hospital in first $\mathbf{4 8}$ hours

$P=0.065$ Major complications

$P=0.0037$ All complications

\section{RECURRENCES OF HERNIA}

The other important clinical complication is the late one of recurrences. As mentioned earler, this was measured only in the hernia patients. Eighty-two were seen by surgeons and another five replied to a letter asking about any recurrence of the hernia. The total response rate was $82.9 \%$. The mean follow-up after operation for the two lengths-of-stay groups was 2.3 years. A total of six recurrences were evenly divided between the two length-of-stay groups. The risk of recurrence per man-year at risk

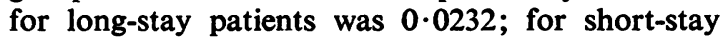
patients it was 0.0199. After adjustment for the number of years at risk the difference between the recurrence rates for long- and short-stay patients was not significant (standard normal deviates, $Z=0.463)$. This is discussed more fully elsewhere (Adler, 1977b).

\section{LENGTH OF CONVALESCENCE}

Table 3 shows the mean number of days from the day of the operation until return to work or normal activity. Men and women in the short-stay group had a longer convalescence than those in the longstay group, but the differences were not statistically significant. However, the differences between men and women patients were significant for both longstay and short-stay groups. Not all women patients were in full-time employment, so the length of convalescence for women was compared by type of employment. It was found that housewives went back to their duties earlier than women out at work full-time or part-time. It is therefore possible that this accounted for the significant differences between men and women long-stay and short-stay patients. This is substantiated by the fact that the difference in length of convalescence for men and women in full-time employment was not statistically significant for either length-of-stay group. Table 4 shows the cost implications of time off work.

Table 3 Mean number of days between operation and return to work or normal activity

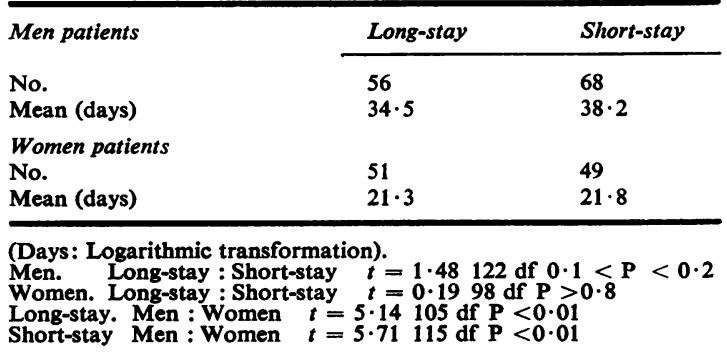

Table 4 Loss of productive time: community cost

\begin{tabular}{lcc}
\hline Condition & Long-stay & Short-stay \\
\hline Inguinal hernia & $£ 254 \cdot 67$ & $£ 274 \cdot 26$ \\
Varicose veins & $£ 83 \cdot 49$ & $£ 87 \cdot 12$ \\
\hline
\end{tabular}

\section{STATUTORY SERVICE COSTS}

Table 5 summarises the costs to the statutory services for inguinal hernia and varicose vein patients. Table 6 summarises the social cost per case. The difference in cost for men hernia patients was $£ 6.90$ but for women vein patients it was $£ 19.62$. The savings per case for men patients in particular were small; the savings to the statutory services are similar for both conditions and were virtually offset by longer convalescence. The savings per case were greater for women but this was largely because the convalescence periods of long-stay and shortstay patients were similar. 
Table 5 Costs of statutory services

\begin{tabular}{|c|c|c|}
\hline & Long-stay & Short-stay \\
\hline Inguinal hernia patients & $\varepsilon$ & $\bar{\varepsilon}$ \\
\hline $\begin{array}{l}\text { Hospital costs } \\
\text { Shared } \\
\text { Individual } \\
\text { Outpatient }\end{array}$ & $\begin{array}{r}55.54 \\
13.86 \\
2.04\end{array}$ & $\begin{array}{r}24 \cdot 98 \\
11 \cdot 78 \\
2 \cdot 04\end{array}$ \\
\hline $\begin{array}{l}\text { GP costs } \\
\text { Consultation } \\
\text { Prescription } \\
\text { District nursing service } \\
\text { Home help service }\end{array}$ & $\begin{array}{l}0 \cdot 85 \\
3 \cdot 80 \\
0 \cdot 23 \\
-\end{array}$ & $\begin{array}{l}1 \cdot 21 \\
5 \cdot 32 \\
2 \cdot 56 \\
0 \cdot 22\end{array}$ \\
\hline Total & $£ 76 \cdot 32$ & $£ 48 \cdot 11$ \\
\hline \multicolumn{3}{|l|}{ Varicose vein patients } \\
\hline $\begin{array}{l}\text { Hospital costs } \\
\text { Shared } \\
\text { Individual } \\
\text { Outpatient }\end{array}$ & $\begin{array}{r}52 \cdot 14 \\
17 \cdot 88 \\
2 \cdot 04\end{array}$ & $\begin{array}{r}24 \cdot 98 \\
15 \cdot 20 \\
2 \cdot 04\end{array}$ \\
\hline $\begin{array}{l}\text { GP costs } \\
\text { Consultation } \\
\text { Prescription } \\
\text { District nursing service } \\
\text { Home help service }\end{array}$ & $\begin{array}{l}0.41 \\
4.56 \\
0.03 \\
0.26\end{array}$ & $\begin{array}{l}0 \cdot 85 \\
4.56 \\
3.46 \\
2 \cdot 95\end{array}$ \\
\hline Total & $£ 77 \cdot 32$ & $£ 54.03$ \\
\hline
\end{tabular}

Table 6 Social cost per case

\begin{tabular}{|c|c|c|}
\hline & Long-stay & Short-stay \\
\hline Inguinal hernias (men) & $\varepsilon$ & $\varepsilon$ \\
\hline $\begin{array}{l}\text { Cost to statutory services } \\
\text { Cost to patient and family } \\
\text { Cost to community }\end{array}$ & $\begin{array}{r}76 \cdot 32 \\
0 \cdot 03 \\
254 \cdot 89\end{array}$ & $\begin{array}{r}48 \cdot 11 \\
1 \cdot 44 \\
274 \cdot 79\end{array}$ \\
\hline Total & $£ 331 \cdot 24$ & $£ 324.34$ \\
\hline $\begin{array}{l}\text { Varicose veins (women) } \\
\text { Cost to statutory services } \\
\text { Cost to patient and family } \\
\text { Cost to community }\end{array}$ & $\begin{array}{r}77 \cdot 32 \\
2 \cdot 00 \\
85 \cdot 75\end{array}$ & $\begin{array}{l}54 \cdot 03 \\
1 \cdot 34 \\
90 \cdot 08\end{array}$ \\
\hline Total & $£ 165.07$ & $£ 145.45$ \\
\hline
\end{tabular}

\section{ATTITUdeS}

\section{PATIENTS}

Before admission there was no significant difference in the scores of the two groups of patients measuring their attitudes towards early discharge. However, five days after their operations and at follow-up, short-stay patients were significantly more in favour of the scheme than long-stay patients. Fourteen days after the operation, when patients were asked whether they would have liked to stay in hospital for a longer or shorter time, $65 \%$ of the short-stay patients compared with $58 \%$ of the long-stay patients were content with the period they had spent in hospital. This difference is not statistically significant and suggests that patients liked the type of care they experienced.

\section{FAMILIES}

By contrast with the patients, the families of the short-stay group were less enthusiastic about the policy of early discharge. This difference was statistically significant.

\section{GENERAL PRACTITIONERS}

The great majority of doctors (89.7\%) approved strongly, or with some reservations, of early discharge after surgery as a general policy. Sixty-five per cent of the general practitioners who had looked after at least one short-stay patient said that the policy had had no effect on their workload; $35 \%$ said that it had increased their workload.

\section{DISTRICT NURSES}

Forty-six $(92 \%)$ of the nurses who were interviewed said that their work pattern had not changed in any way. The other four $(8 \%)$ felt that more work and time was involved as a result of changed visiting order, and that other patients were held up. The majority of nurses $(92 \%)$ thought that there were advantages for families of short-stay patients, and for the patients themselves $(96 \%)$.

\section{HOUSEHOLD DISRUPTION AND EFFECTS ON OTHER PATIENTS}

More of the short-stay women patients reported a change in the person helping with shopping, cooking, cleaning, washing, and looking after the children. The only significant difference was for shopping. Once the patients had returned home, significantly more short-stay women patients also reported gettingo outside help. So that patients in the study could get the care they needed, some other patients with home helps either lost help or received less, or received it at a different time or on a different day. Forty-seven other patients lost 75 hours of help as a result of the care directed to study patients.

\section{Discussion}

The general analytical framework of this study is cost-effectiveness. The effectiveness is measured by the clinical outcome (complications, length of convalescence, and recurrences), and by the attitudes of both patients and health service staff. Attitudes have been considered as part of the measure of effectiveness, because the patient's degree of satisfaction with the care he has received is an inherent part of good medical care. Similarly, if doctors and district nurses caring for patients discharged early were unhappy with the scheme, the quality of care might deteriorate. Indeed, if the patients and providers disliked the policy strongly enough, it would no more be possible to implement it than it would if the numbers of complications were unacceptably high.

A difference in cost per case was identified for the two conditions; the short-stay alternative was cheaper. The costs for men hernia patients were a much heavier burden on the community than on 
the statutory services, and for women varicose vein patients the loss of normal activity was of significant economic importance. Costs to the statutory services accounted for most of the difference in costs per case between the two length-of-stay groups for both conditions; again, the short-stay patients used fewer resources. The additional domiciliary care needed was not nearly enough to offset savings to the hospital, achieved mainly by eliminating the 'hotel' component from the conventional length of hospital stay for these conditions. Costs to patients and their families accounted for a very small proportion of the total and an insignificant element of the difference. The intangible cost to study patients (in the form of domestic reorganisation) and the disruptions among other patients receiving home help services might be considered to detract from some of the financial advantages of short-stay.

The clinical outcome for each of the two sets of patients with the two conditions was measured according to three criteria. One of these, convalescence time, has already been taken into account in estimating the costs of treatment. The indicators of outcome were not aggregated into an overall index, because this would have meant using researchers' or clinicians' (or possibly patients') judgements in assigning weights to the individual components of outcome. However, no significant differences were observed on either criterion, and the alternatives were judged equally acceptable on clinical outcome. The measurement of patients' and providers' attitudes also suggests no clear advantage for either of the two lengths of stay.

It is therefore apparent that the only difference between the long-stay and the short-stay group is that of cost, and that the advantage, both overall and for the statutory providers, lies with the short-stay policy.

The existence of a treatment option with a lower cost per case and a comparable outcome means that better value might be obtained from the health service budget. Providing an accurate estimate of the value of early discharge involves specifying the opportunity cost of resources currently deployed to care for these patients. Without this, we must assume that current prices are a reasonable approximation to opportunity cost. The saving to the statutory services, estimated at $£ 25.72$ per case for both conditions, is thus a rough measure of the value of the resources which would be saved if each hernia or varicose vein patient at present treated were to be discharged after three days. If it were possible, for the study year, to treat all these cases as short-stay patients, the value of resources released would be $£ 25 \times 123763^{*}$, or $£ 3.09$ million. At August, 1976, prices, this is a saving of $£ 6.06$ million. Contraindications, private patients, and other exclusions reduce the proportion of the population actually eligible for shorter stay after such surgery, and there are also operational constraints, for example, theatre time or home helps; to that extent, these figures will obviously be reduced.

No attempt has been made to inject a rental element into the revenue costs itemised above: the implications of early discharge for capital savings are thus of a long-term nature, and will depend greatly on future building plans. On the basis of the above figures for England and Wales, it might be possible to redeploy or close as many as 800 beds if a short-stay policy were implemented for these two conditions alone. The value of this would depend very much on where the reductions were made.

It should be emphasised that such figures are estimates of the value of resources released: they are not likely to accrue to the health service as a cash benefit except where those resources are cashed inby closing beds and not replacing staff. Only in this way would early discharge allow significant amounts of money to be saved from the existing budget. A second possible accompaniment to early discharge might actually result in increased costs to the health service, although the health service would be doing more at the same time. In a situation where beds released as a result of short-stay policy were used to increase hospital throughput, the total costs might well increase.

A third possibility would be an early discharge policy accompanied by no change in throughput; with the beds released remaining unoccupied. In this situation there would be some savings to the health service, principally of the individual components of care, although most of the 'hotel' services would not be reduced.

The economic implications of early discharge depend on the degree to which it is adopted, and on whether such a policy is intended to save money or extend services at no extra cost. In practice, some mixture of the two seems likely.

This study was supported in part by the Department of Health and Social Security. We thank the staff of the local hospitals, particularly the three surgeons; the general practitioners; the local authority staff; the patients; and the field workers for enabling this study to be carried out. We also thank Elizabeth Cooper, who was responsible for co-ordinating the study, and $\mathrm{Mr} \mathrm{H}$. Kasap and

*Total discharge for varicose veins of lower extremity and inguinal hernias (Department of Health and Social Security and Office of Population Censuses and Surveys, 1971). 
Mr T. Swan for statistical assistance. Some of this work formed part of an M.D. thesis (University of London) by M. W. Adler.

Reprints from: M. W. Adler, Department of Community Medicine, Middlesex Hospital Medical School, London W1N 8AA.

\section{References}

Abel-Smith, B. (1976). Value for Money in Health Services. Heinemann: London.

Adler, M. W., Waller, J. J., Day, I., Kasap, H. S., King, C., and Thorne, S. C. (1974). A randomised controlled trial of early discharge for inguinal hernia and varicose veins-some problems of methodology. Medical Care, 12, 541-547.

Adler, M. W. (1977a). Randomised controlled trial of early discharge for inguinal hernia and varicose veins. Annals of the Royal College of Surgeons of England, 59, 251-254.

Adler, M. W. (1977b). A randomised controlled trial of early discharge for inguinal hernia and varicose veins. MD. thesis. University of London.

Blodgett, J. B., and Beattie, E. J. (1946). Early postoperative rising. A statistical study of hospital complications. Surgery, Gynecology and Obstetrics, 82, 485-489.

Blodgett, J. B., and Beattie, E. J. (1947). The effect of early postoperative rising on the recurrence rate of hernia. Surgery, Gynecology and Obstetrics, 84, 716-718.

Chant, A. D. B., Hishon, S., Spencer, T., Whitcher, D., and Brooks, A. (1972). Another approach to the hernia waiting list. Lancet, 2, 1017-1018.

Clarke, M., and Bennett, A. E. (1971). Problems in the measurement of hospital utilisation. Proceedings of the Royal Society of Medicine, 64, 795-798.

Dean, D., and Wilkinson, B. R. (1969). Outpatient operations-as the general practiitioner sees it. British Medical Journal, 1, 176-177.

Department of Health and Social Security and Office of Population Censuses and Surveys (1971). Report on Hospital In-patient Enquiry. HMSO: London.

Doran, F. S. A., White, M., and Drury, M. (1972). The scope and safety of short-stay surgery in the treatment of groin hernias and varicose veins. British Journal of Surgery, 59, 333-339.

Drury, M., Doran, F. S. A., and White, M. (1973). Short-stay surgery and general practice. Journal of the Royal College of General Practitioners, 23, 55-58.

Echeverri, O., Manzano, G., Gomez, A., Quintero, M., and Cobo, A. (1972). In hospital or at home? A feasibility study. International Journal of Health Services, 2, 101-110.
Farquharson, E. L., (1955). Early ambulation with special reference to herniorrhaphy as an outpatient procedure. Lancet, 2, 517-519.

Fisher, R. A. (1970). Statistical methods for research workers. Oliver and Boyd: Edinburgh.

Gerson, L. W., and Berry, A. F. E. (1976). Psychosocial effects of home care. Results of a randomised controlled trial. International Journal of Epidemiology, 5, 159-165.

Heasman, M. A. (1964). How long in hospital? A study in variation in duration of stay for two common surgical conditions Lancet, 2, 539-541.

Hockey, L. (1970). District nursing sister attached to hospital surgical department. British Medical Journal, 1, 169-171.

Iles, J. D. H. (1965). Specialisation in elective herniorrhaphy. Lancet, 1, 751-755.

King Edward's Hospital Fund for London (1973) Accounting for health. Report of a working party on the application of economic principles to health service management. King's Fund: London.

Likert, R. (1932). A technique for the measurement of attitudes. Archives of Psychology, 140.

Lord, P. H. (1969). A day case procedure for the cure of third degree haemorrhoids. British Journal of Surgery, 56, 747-750.

Mason, A., Perry, J., and Stegg, J. (1973). Disease costing in hospitals. Mimeo. Medical Research Council and Department of Health and Social Security Epidemiology and Medical Care Unlt, Northwick Park Hospital, Middlesex.

Morris, D., Ward, A. M., Handyside, A. J. (1968). Early discharge after hernia repair. Lancet, 1, 681-685.

Osgood, C. E., Suci, G. J., and Tannenbaum, D. G. (1951). The measurement of meaning. University of Illinois Press: Chicago.

Rice, D. P. (1966). Estimating the cost of illness. US Department of Health, Education and Welfare: Washington DC.

Ries, E. (1899). Some radical changes in the after treatment of celiotomy cases. Journal of the American Medical Association, 33, 454-456.

Ruckley, C. V., MacLean, M., Smith, A. N., Small, W. P., and Falconer, C. W. A. (1971). Team approach to early discharge and outpatient surgery. Lancet, 1, 177-180.

Ruckley, C. V., Ludgate, C. M., MacLean, M., Epsley, A. J. (1973). Major outpatient surgery. Lancet, 2, 1193-1196.

Russell, I. T., Devlin, H. B., Fell, M., Glass, N. S., and Newell, D. J. (1977). Day case surgery for hernias and haemorrhoids. A clinical, social, and economic evaluation. Lancet, 1, 844-847.

Stephens, F. O., and Dudley, H. A. F. (1961). An organisation for ou:tpatient surgery. Lancet, 2, 10421046.

South-west Metropolitan Regional Hospital Board (1972). Cost returns. SWMRHB: London. 